\title{
Der Autor
}

Dr. Arne-Patrik Heinze ist seit dem Jahr 2004 bundesweit als Dozent im Öffentlichen Recht unter anderem im Bereich der Vorbereitung auf die juristischen Examina tätig. Zudem arbeitet er seit 2008 als Rechtsanwalt und ist geschäftsführender Gründungsgesellschafter der Kanzleien Rechtsanwälte Dr. Heinze \& Partner Deutschland und Rechtsanwälte Dr. Heinze \& Partner Schweiz. Heinze ist als Fachanwalt für Verwaltungsrecht bundesweit auf Prüfungsanfechtungen (Staatsexamina Jura, Notarielle Fachprüfungen, Steuerberaterprüfungen, universitäre Prüfungen usw.), Studienplatzklagen und Verfassungsbeschwerden sowie Verfahren beim EGMR spezialisiert. Zudem betreut er Mandate im Allgemeinen Verwaltungsrecht und im Öffentlichen Baurecht.

Richterinnen und Richter, Professorinnen und Professoren, Rechtsanwältinnen und Rechtsanwälte uns sonstige Juristinnen und Juristen haben bei Heinze Öffentliches Recht und das System der juristischen Dogmatik erlernt. Er war bis zum Jahr 2013 geschäftsführender Gesellschafter der BeckAkademie (Verlag C.H. Beck), die er als Gründungsgesellschafter mit Kollegen bundesweit etabliert hat. In den Jahren 2013 - 2015 war er verbeamteter Professor für Öffentliches Recht an einer Polizeiakademie. Die Professur gab er zugunsten der Anwaltstätigkeit auf, da es in Deutschland nach dem anwaltlichen Berufsrecht neben der Anwaltstätigkeit zwar zulässig ist, , unechte“ Professuren wie eine Honorarprofessur oder eine Professur an Privatinstitutionen innezuhaben - nicht jedoch dauerhaft eine „echte“ Professur im Beamtenverhältnis. Dennoch ist Heinze der Wissenschaft und der Lehre aus Leidenschaft zur juristischen Dogmatik treu geblieben, kombiniert diese mit seiner Anwaltstätigkeit, publiziert regelmäßig und wird vor allem als Experte im Prüfungsrecht sowie im Bereich der Studienplatzklagen immer wieder von diversen renommierten Medien aus dem Fernseh-, Radio-, Online- und Printbereich angefragt.

Dr. Arne-Patrik Heinze, LL.M.

Rechtsanwälte Dr. Heinze \& Partner Partnerschaftsgesellschaft mbB

info@heinze-rechtsanwaelte.de

www.heinze-rechtsanwaelte.de 
